\title{
On the weak impact of the 26 December Indian Ocean tsunami on the Bangladesh coast
}

\author{
M. Ioualalen ${ }^{1}$, E. Pelinovsky ${ }^{2}$, J. Asavanant ${ }^{3}$, R. Lipikorn ${ }^{3}$, and A. Deschamps ${ }^{1}$ \\ ${ }^{1}$ Geosciences Azur, IRD-CNRS-UPMC-UNSA, Villefranche-sur-mer, France \\ ${ }^{2}$ Institute of Applied Physics, Russian Academy of Sciences, Nizhny Novgorod, Russia \\ ${ }^{3}$ Department of Mathematics, Faculty of Science, Chulalongkorn University, Bangkok, Thailand
}

Received: 12 October 2006 - Revised: 17 January 2007 - Accepted: 19 January 2007 - Published: 26 January 2007

\begin{abstract}
The 26 December 2004 Indian Ocean tsunami damaged severely most of the Gulf of Bengal's coastal areas, but the coast of Bangladesh which stands at the edge of an extraordinarily extended continental shelf. This latter feature has been built through huge discharges of river sediments along the Brahmaputra and Ganges rivers. As a result of this enormous discharge, another interesting feature of the area is the deep underwater Canyon, connected with the estuaries, running NE-SW from $25 \mathrm{~km}$ off the coast towards the continental slope.

We investigate here how these two geological features may have modified/perturbed the Indian ocean tsunami propagation and impact on the Coast of Bangladesh. For that purpose we have realized an ensemble of numerical simulations based on Funwave Boussinesq numerical model and a validated coseismic source. It is found, at first order, that the extended shallow bathymetric profile of the continental shelf plays a key role in flattening the waveform through a defocussing process while the Canyon delays the process. The wave evolution seems to be related at first order to the bathymetric profile rather than to dynamical processes like nonlinearity, dispersion or bottom friction.
\end{abstract}

\section{Introduction}

The megathrust earthquake that struck offshore Sumatra island on 26 December 2004 was one of the largest earthquake ever recorded. From its epicenter, located $80 \mathrm{~km}$ west of the coast of Northern Sumatra, the rupture propagated nearly northward over a distance of $1200-1300 \mathrm{~km}$ along the Andaman/Sunda trench in about 8-10 min (Ammon et al., 2005; Lay et al., 2005) (Fig. 1). The $M_{w} \simeq 9.3$ earthquake triggered a tsunami that was one of the most devastating natural dis-

Correspondence to: M. Ioualalen

(Mansour.Ioualalen@geoazur.obs-vlfr.fr) asters ever witnessed in modern history, causing more than 292000 fatalities in 12 countries bordering the Indian Ocean basin. The largest tsunami runups, over $30 \mathrm{~m}$, occurred south of Banda Aceh, Sumatra, whose shore is closest to the epicenter, only about $10 \mathrm{~min}$ away in terms of tsunami propagation time (Fig. 1). This area suffered from the majority of fatalities (almost 230000 dead or missing) and the most intense and widespread destruction. The next most heavily impacted area was the coast of Thailand, followed by India and Sri Lanka. As far as Bangladesh is concerned, two casualties had been reported after the tsunami, a four-year old boy and his young brother reported missing in Barisal (Fig. 2) (Uddin, 2005). They were traveling in a trawler off the coast of Barisal when the trawler capsized. Otherwise, there is no available runup data or even eye-witnesses that could provide any information about the wave amplitude or sequence of waves on the coast. Consequently, we perform numerical sensitivity tests to check the effects of various physical processes on the mode of propagation and amplification of the tsunami, e.g. the bathymetry, dispersion, nonlinearity, bottom friction and the tsunami direction of radiation. However, it is fair to note that despite the lack of observations in the area, the ensemble of numerical simulations and the methodology that we use here has been already validated for the event, e.g., the co-seismic source and the numerical procedure (Grilli et al., 2006; Ioualalen et al., 2006).

\section{The best-fitted coseismic source triggering the tsunami}

The earthquake occurred at $0 \mathrm{~h} 58^{\prime} 53^{\prime \prime} \mathrm{UTC}$ off the northwestern coast of Sumatra, Indonesia, at $95^{\circ} 51^{\prime}, 3^{\circ} 25^{\prime}$ (Fig. 1). Numerous GPS stations and seismic inversion models indicate that the rupture propagated approximately northward from the epicenter, along a 1200-1300 km segment of the Andaman/Sunda trench with an average rupture speed

Published by Copernicus GmbH on behalf of the European Geosciences Union. 


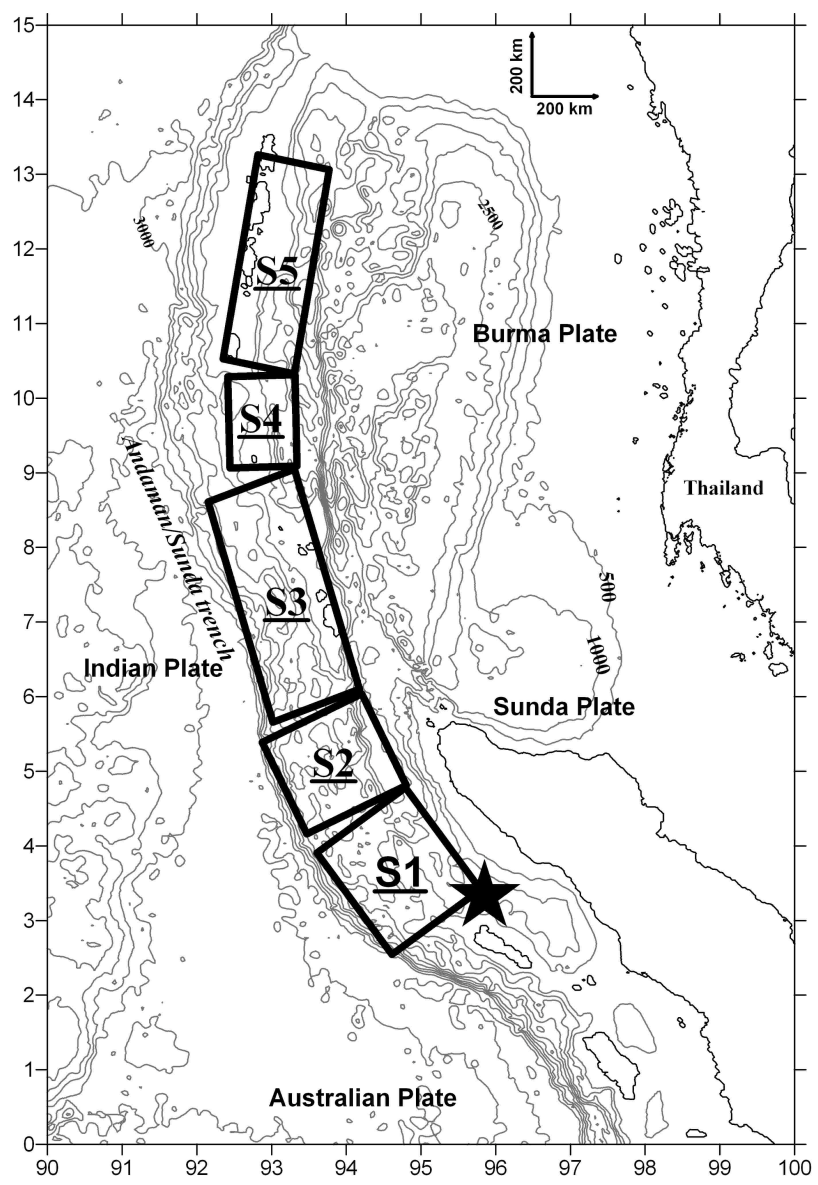

Fig. 1. ETOPO-2 bathymetry around the 26 December 2004 earthquake location (star sign) contoured at $500 \mathrm{~m}$ intervals. Rectangles S1-S5 represent the Okada (1985) dislocation model fault segments (Table 1) computed by Grilli et al. (2006).

of $2.5-3 \mathrm{~km} / \mathrm{s}$, causing up to $\sim 6 \mathrm{~m}$ of bottom subsidence and $\sim 10 \mathrm{~m}$ of uplift over a region $100-150 \mathrm{~km}$ wide across the subduction area (Ammon et al., 2005; Lay et al., 2005). Seismic inversion and GPS records further indicate that fault slip ranged between 15 and $25 \mathrm{~m}$, with a gradual decrease northward from the epicenter (Vigny et al., 2005). Based on these observations, Grilli et al. (2006) further calibrated a five-segment Okada (1985) dislocation source (Figs. 1, 2; Table 1) using available hydrodynamic data, in particular the sea level anomalies recorded by the JASON-1 altimeter, which happened to transit over the area spawned by the spreading tsunami about 2 hours after the earthquake initiation, during cycle 109 of its pass 129 (Smith et al., 2005), and several digital tide gauge records installed along the Gulf of Bengal coasts (Merrifield et al., 2005). This source has been tested and validated by Ioualalen et al. (2006) for the Thailand case study. They were able to reproduce most of the runup features over the Andaman coast of Thailand. The

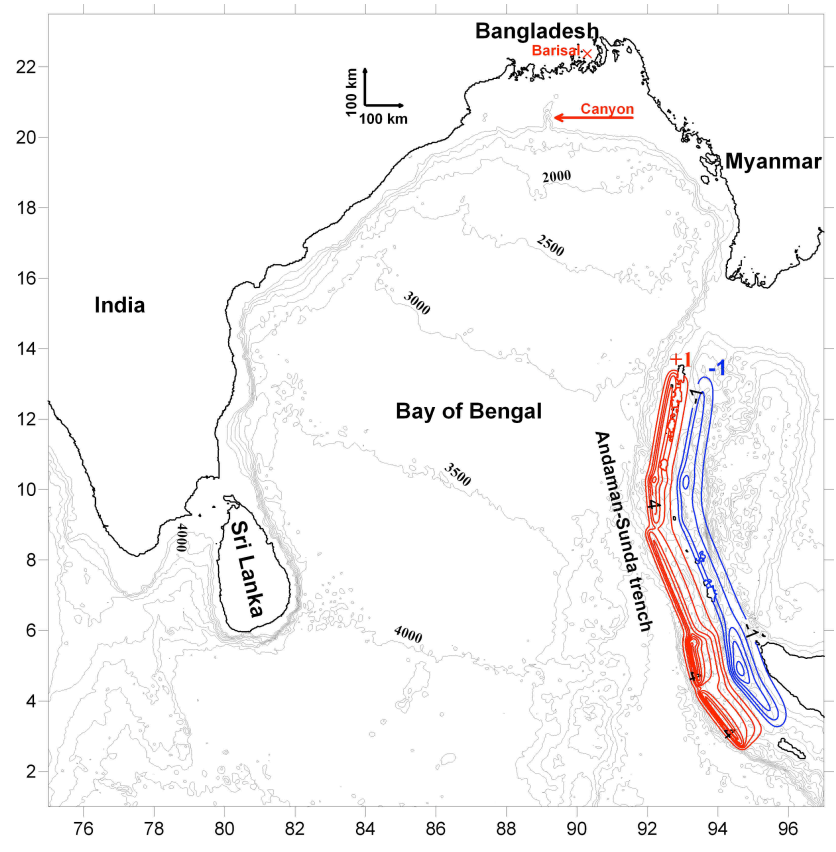

Fig. 2. Initial surface elevation for the tsunami source developed by Grilli et al. (2006) and Ioualalen et al. (2006) based on five Okada (1985) dislocation segments (S1-S5; Table 1, Fig. 1). Red lines represent uplift and blue lines represent subsidence, both at $1 \mathrm{~m}$ contour intervals in the range -5 to $+8 \mathrm{~m}$. The background bathymetry is plotted in grey at $500 \mathrm{~m}$ contour intervals. The red cross in Bangladesh locates Barisal where the two casualties of the tsunami were reported.

runups obtained in a predictive mode (the simulations were not constrained by runup observations) fitted observations at a relatively high degree of accuracy. These results encourage us to apply the procedure to the Bangladesh case study despite the lack of tsunami observations along the coast of Bangladesh. Furthermore, the Grilli et al. (2006) and Ioualalen et al. (2006) calibrated source yields a wave profile that is coherent in amplitude and phase with the northern part of the JASON-1 signal: the two associated northern source segments (Table 1) are mostly responsible for the Bangladesh coastal effects.

\section{The numerical procedure and the computational domain}

Reliable numerical simulations of tsunami coastal effects depend on (i) a best-fit geophysical source (ii), an accurate ocean bathymetry and coastal topography, and (iii) a tsunami propagation and well-validated runup model. The 1 ' grid spacing computational domain is derived from the 2' ETOPO-2 bathymetry and topography (ETOPO-2, 2001). The computational domain, extending from $75^{\circ} \mathrm{E}$ to $97^{\circ} \mathrm{E}$ in longitude and from $1^{\circ} \mathrm{N}$ to $23.5^{\circ} \mathrm{N}$ in latitude, covers the 
Table 1. Okada (1985)'s input parameters for 5 tsunami source segment in Fig. 1: time delay of segment rupture from earthquake time $\tau$ (a $60 \mathrm{~s}$ rising time is added); longitude and latitude of segment centroid $\left(x_{o}, y_{o}\right)$; the centroid depth $d$, the fault strike angle $\varphi$ (clockwise from North); the fault rake angle $\lambda$ (counterclockwise from strike); the fault dip angle $\delta$ (dip counted clockwise from the horizontal plane); the maximum fault slip $\Delta$; the segment length along and width across $(L, W)$; and the medium shear modulous $\mu$. Note that, in the simulation, the slip is maximum at the segments' centroid and drops by $50 \%$ at a radius of $L$ from it through a Gaussian law.

\begin{tabular}{llllll}
\hline Parameters & S1 & S2 & S3 & S4 & S5 \\
\hline$\tau(\mathrm{s})$ & 60 & 272 & 588 & 913 & 1273 \\
$x_{o}$ & $94.57^{\circ} \mathrm{E}$ & $93.90^{\circ} \mathrm{E}$ & $93.21^{\circ} \mathrm{E}$ & $92.60^{\circ} \mathrm{E}$ & $92.87^{\circ} \mathrm{E}$ \\
$y_{o}$ & $3.83^{\circ} \mathrm{N}$ & $5.22^{\circ} \mathrm{E}$ & $7.41^{\circ} \mathrm{E}$ & $9.70^{\circ} \mathrm{E}$ & $11.70^{\circ} \mathrm{E}$ \\
$d(\mathrm{~km})$ & 25 & 25 & 25 & 25 & 25 \\
$\varphi$ & $323^{\circ}$ & $348^{\circ}$ & $338^{\circ}$ & $356^{\circ}$ & $10^{\circ}$ \\
$\lambda$ & $90^{\circ}$ & $90^{\circ}$ & $90^{\circ}$ & $90^{\circ}$ & $90^{\circ}$ \\
$\delta$ & $12^{\circ}$ & $12^{\circ}$ & $12^{\circ}$ & $12^{\circ}$ & $12^{\circ}$ \\
$\Delta(\mathrm{m})$ & 18 & 23 & 12 & 12 & 12 \\
$L(\mathrm{~km})$ & 220 & 150 & 390 & 150 & 350 \\
$W(\mathrm{~km})$ & 130 & 130 & 120 & 95 & 95 \\
$\mu(\mathrm{Pa})$ & $4 \times 10^{10}$ & $4 \times 10^{10}$ & $4 \times 10^{10}$ & $4 \times 10^{10}$ & $4 \times 10^{10}$ \\
\hline
\end{tabular}

entire Gulf of Bengal and most of the significant vertical co-seismic deformation (Fig. 3). Considering the relatively important wavelength (approximately $150 \mathrm{~km}$ at the generation, Ioualalen et al. (2006)), we may conjecture that we have a reasonable grid spacing for the Bangladesh continental shelf and the Canyon connecting the submarine delta of the Ganges-Brahmaputra to the Bengal deep-sea fan. The Canyon, also named "Swatch of No Ground", is running NESW at around $25 \mathrm{~km}$ south of the coast along the continental shelf. It has a maximum depth of $1200 \mathrm{~m}$, with depths at its edge ranging between $60-800 \mathrm{~m}$. It has a flat floor of 5 to $7 \mathrm{~km}$ wide (3 grid points) and walls of about $12^{\circ}$ inclination yielding a better grid resolution near the surface. Funwave numerical model is fully nonlinear and dispersive, retaining information to leading order in frequency dispersion $O\left[(k h)^{2}\right]$ and to all orders in nonlinearity $a / h$ (where $k$ denotes an inverse wavelength scale, $a$ denotes a wave amplitude, and $h$ denotes a water depth) (Wei and Kirby, 1995; Wei et al., 1995). Instead of tracking the moving boundary during wave runup/rundown on the beach or coastlines, Funwave model treats the entire computational domain as an active fluid domain by employing an improved version of the slot or permeable-seabed technique. This is sometimes called the moving shoreline algorithm proposed by Chen et al. (2000) and Kennedy et al. (2000) for simulation of runup. Basic idea behind this technique is to replace the solid bottom where there is little or no water covering the land by a porous seabed or to assume that the solid bottom contains narrow slots. This is incorporated in terms of mass

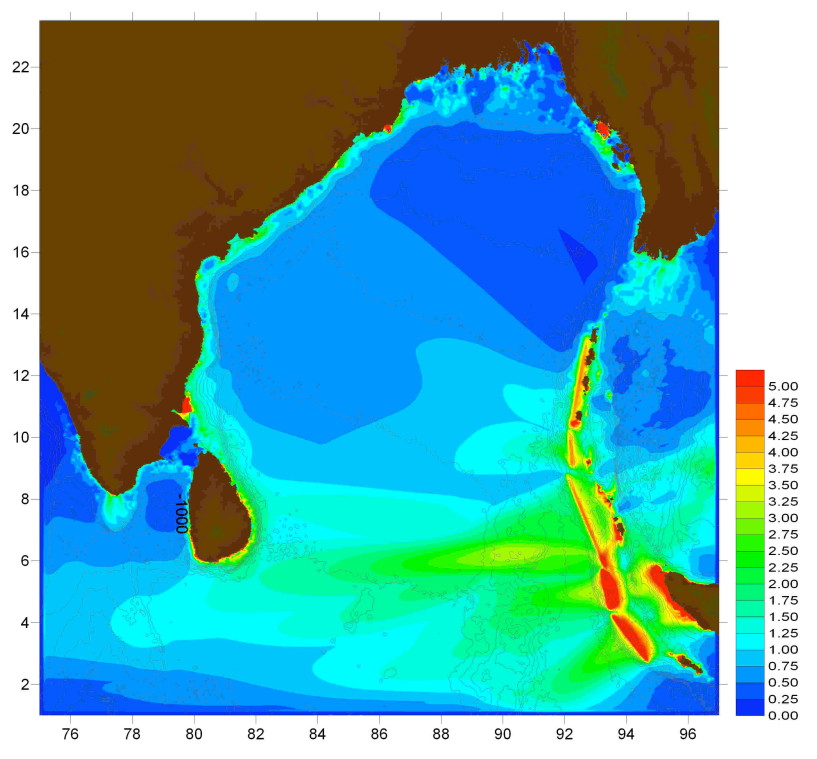

Fig. 3. Maximum surface elevation for the Gulf of Bengal. The background bathymetry is plotted in grey at $500 \mathrm{~m}$ contour intervals.

flux and free surface elevation in order to conserve mass in the presence of slots. The model includes bottom friction, energy dissipation to account for the wave breaking and a subgrid turbulence scheme. The bottom friction is modeled by the use of the quadratic law with bottom friction coefficient between $1.0 \times 10^{-3}$ to $5.0 \times 10^{-3}$. The subgrid turbulence is modeled in terms of Smagorinsky-subgrid turbulent mixing type to account for the effect of underlying current field. The energy dissipation due to wave breaking in shallow water is treated by the use of momentum mixing terms. The associated eddy viscosity is essentially proportional to the gradient of the horizontal velocity which is strongly localized on the front face of the breaking wave. The validation and verification of this breaking wave formulation for short wave shoaling and runup can be found in (Chen et al., 2000; Kennedy et al., 2000). Without the bottom dissipation and wave breaking terms, the energy flow into the shallow water region may remain large and would artificially amplify at the coast (Knight , 2006).

\section{The numerical results and sensitivity tests}

As mentioned above, the lack of objective runup observations constrain us to perform a reference simulation based on the source of Grilli et al. (2006) and Ioualalen et al. (2006) and funwave Boussinesq model, and then to proceed to sensitivity test. Besides, we are interested in the mode of propagation of the tsunami within the continental shelf and Canyon. As a comparison with northern India, the wave amplitudes offshore are quite similar off the northern India as off 


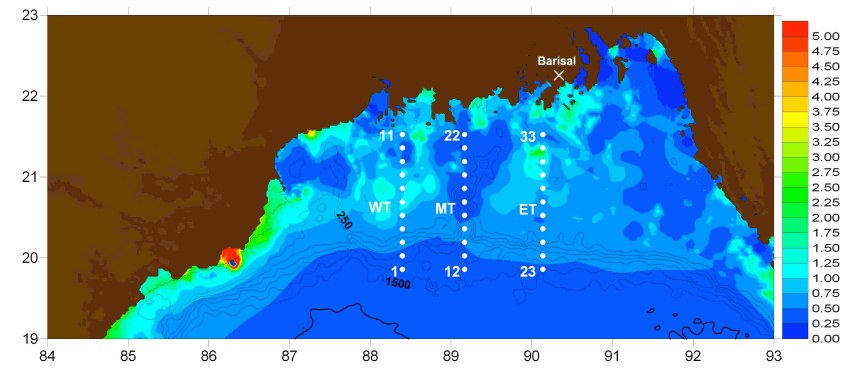

Fig. 4. Maximum surface elevation for the Bangladesh area. The background bathymetry is plotted in grey at $500 \mathrm{~m}$ contour intervals. The dots correspond to the locations of virtual tide gauges recorded as time series in the simulation: WT is for Western Track, MT for Middle Track along the Canyon and ET for Eastern Track.

Bangladesh. However, along the Bangladesh coast, the wave amplitude is relatively weak ( $1 \mathrm{~m}$ in average) compared to the other regions of the Gulf of Bengal (Fig. 3). At this stage we address the question on the relation between the wave amplitude weakness and the directivity of the wave. Along the subduction area (Fig. 1), the fault is oriented almost south-north such that Bangladesh is not aligned in the direction of radiation of the wave which is almost oriented east-west (Fig. 3). However, this cannot fully explain the weak maxima of amplitude because the same statement applies for the northern part of India which experiences significant maximum wave heights $\left(2-3 \mathrm{~m}\right.$ and larger locally around $20^{\circ} \mathrm{N}$ because of site effects). Along the Indian coast, to the north, the high waves disappear for an extending shelf. In that context, considering the large tsunami wavelength, the shoaling effects are predominant in the wave amplification at northern Indian coast. For Bangladesh the wave has still a larger distance of propagation before reaching the coast after the shoaling process has been established past the continental slope. To the north and eastward, the wave height is larger off the coast and distributed sparsely within the shelf (Fig. 4). This weakness is likely due to the large extension of the shelf where the tsunami wave propagates within a shallow water area. Here the slope of the plateform is very weak (around 0.001) and is unlikely to have serious influence on wave amplification or reflection. On the contrary, the continental slope is clearly one of the key parameter responsible for the wave reflection and hence wave front entering the Bangladesh and Northern India platforms. We have tested three physical mechanisms that might be involved in the wave damping along its propagation in the shelf: (1) dispersion that could eventually split the wave form into higher frequencies or merge them into a smoother signal, (2) nonlinearity which may eventually accelerate the wave breaking in shallow water, and (3) bottom friction which applies more in shallow water and may eventually flatten the wave.
As far as dispersion is concerned, there is no overall differences (Fig. 5, upper panel). In most parts of the shelf and at the coast there is no significant difference except locally where dispersion amplifies the tsunami amplitude. Still the highest maxima of wave amplitude are scattered within the shelf. Locally dispersion amplifies the wave height probably because of the merging of high frequency modes yielding an overall more energetic envelop or main wave. Thus dispersion cannot explain the confinement of maxima of amplitude within the continental shelf.

As expected, nonlinear effects are visible in shallow water outside the Canyon area (Fig. 5, middle panel). In overall, nonlinearity amplifies the maxima of amplitude. As a consequence, nonlinearity cannot explain the weak tsunami amplitudes on the shelf and at the coast of Bangladesh.

As expected also, bottom friction applies mainly in shallow water and does not contribute to the wave amplitude along the Canyon (Fig. 5, bottom panel). This is enhanced by the fact that the propagating wave along the Canyon observes a highest maximum wave height at the coast (between $89.3^{\circ} \mathrm{E}$ and $90.7^{\circ} \mathrm{E}$ ). On the overall, bottom friction tends to damp the tsunami signal. However, the damping applies everywhere in shallow water even in the northern Indian coast at the same rates, i.e. there is no accumulation of friction effect. Consequently, there is no reason that bottom friction is responsible for the amplitude weakness in the shelf and coast of Bangladesh.

The three main physical mechanisms experimented above do not seem to be crucial for the presence of a weak tsunami amplitude along the Bangladesh coastline. The main relevant feature is the discrepancy between the amplitude at the Canyon and outside but within the shelf. Outside the Canyon, the maxima of amplitude are located away from the coast. Along and within the Canyon, the amplitude is weak because of deeper waters. In the area surrounding the Canyon (even offshore), the amplitude is higher because shoaling operates in its vicinity. As a result, most of the high tsunami amplitudes at the coast (relatively) are due to the Canyon penetration within the continental shelf (Fig. 4). Although no runup data observations are available, it happened that the only record on the tsunami impact is the death and missing of the two children offshore Barisal coast. Our numerical simulation shows a significant wave height (around $2 \mathrm{~m}$ ) in this area (Fig. 4) which is located consistently at the upstream termination of the Canyon. It results that, at first order, the morphology of the shelf (the bathymetry variation) is crucial for the wave amplitude distribution in the Bangladesh coast. The amplitude response to the bathymetry is immediate (Fig. 6). As expected, at the western track (WT) and the Eastern track (ET) the wave amplifies with decreasing depth. Then, in shallow water, at overall constant depth along the shelf, the wave is not anymore focussing. It flattens and limits the wave amplitude (Fig. 6, upper panel, gauges 9-11, lower panel, gauge 33). The so-called flattening in facts refers to a redistribution of the wave energy from well-established high 

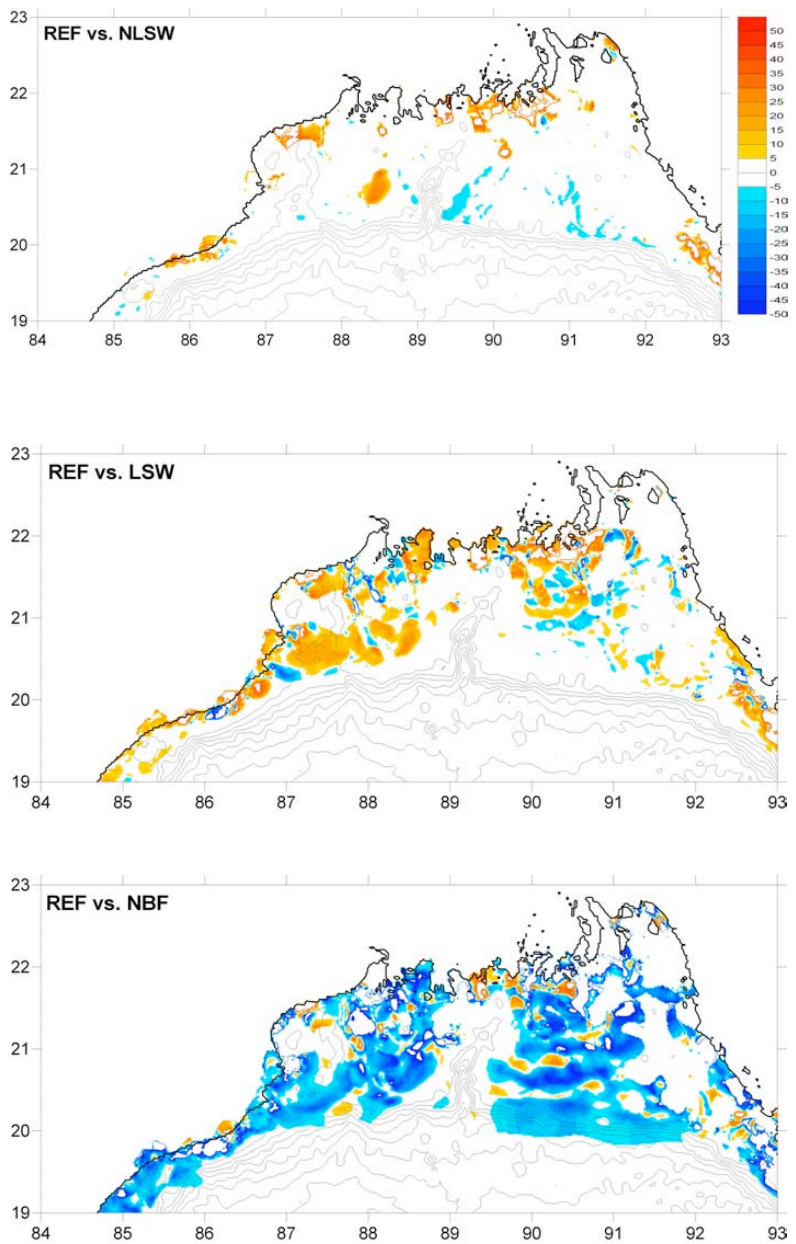

Fig. 5. Relative difference of the maximum of elevation between the reference simulation, Funwave Boussinesq mode, and (upper panel) non dispersive nonlinear shallow water model, NLSW, (middle panel) linear shallow water model, LSW, and (lower panel) with no bottom friction, NBF. The relative difference is expressed in percentage. In order to avoid a noisy signal, the difference has been computed only if the wave height is greater than $0.5 \mathrm{~m}$.

waves to secundary less steep ones. The result is the occurrence of overall lower amplitude wave crests. As stated above, this redistribution process cannot be attributed to nonlinearity or dispersion. Consequently, the only explanation could be a defocussing due to the bathymetry. The statement applies for the first three consecutive simulated wave crests. The defocussing does not occur at the beginning of the shelf despite the presence of shallow water as well. It takes some characteristic time to occur and thus it seems to be related to the extension of the continental shelf. As far as the Middle track is concerned, the process occurs after the wave crosses the Canyon (Fig. 6, Middle panel, gauges 21-22). Due to the Canyon deep water, the defocussing is delayed and the wave propagates in shallow water within a limited portion of conti-
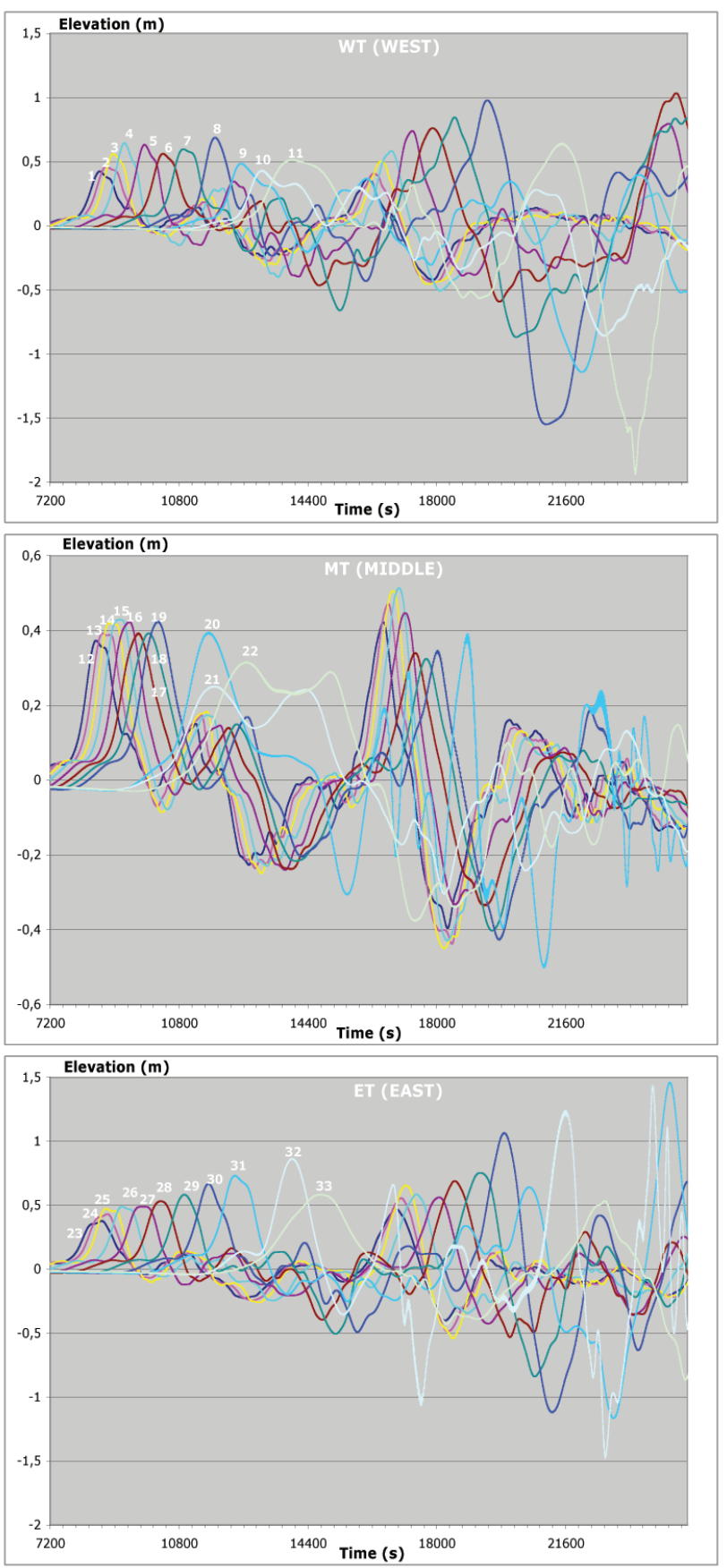

Fig. 6. Recorded time series (in seconds; 10 min separate two successive graduations) representing the sea surface elevation (in meters) at the different virtual tide gauge locations of figure 4 with Boussinesq model. (Upper panel): western track WT locations 1 to 11); (Middle panel): middle track WT (Canyon; from 12 to 22; note the elevation scale is different); (Lower panel): eastern track ET (from 13 to 33).

nental shelf. Consequently, the presence of the Canyon limits the defocussing time scale and allows the wave to be ampli- 
fied at the Canyon termination near/at the coast (Fig. 6, Middle panel, maxima centered in the range $89.3^{\circ} \mathrm{E}$ and $90.7^{\circ} \mathrm{E}$ ).

\section{Conclusions}

We investigated the effects of the 26 December Indian Ocean tsunami on the Bangladeh coast and continental shelf. The lack of observations in the area, mainly due to the weak impact, forced us to perform sensitivity tests to different physical mechanisms with no opportunity to compare the simulation results to observations. However, because the simulation of the event has been validated in other areas of the Gulf of Bengal, we assume that our reference simulation based on Funwave propagation model and a validated source is robust. Then we performed simulations that did not take into account dispersion, nonlinearity and bottom friction. We found that these mechanisms were not crucial for the tsunami wave behaviour in the area. In particular they did not explain why the maxima of wave amplitude are located mainly in the extended continental shelf, except the portion of the wave that has travelled along the Bangladesh underwater Canyon. We eventually found that a defocussing due to an immediate response to the bathymetric profile was responsible for the wave distribution. The defocussing has a tendancy to flatten the wave everywhere in the shelf but at the Canyon termination near the Bangladesh coast where the shelf has a limited extension. The very unique record available (location of the two Bangladesh casualties) is consistant with this statement. Consequently, the underwater Canyon could be responsable for the main impact of the event on the Bangladesh coast because, probably, the associated limited shallow water area did not allow defocussing process to develop at shorter time scale. To synthetise the study, we may assume that the extended continental shelf protects the Bangladesh coast from a tsunami except at the Brahmaputra ganges estuary where the Canyon starts. Besides, the direction of radiation of the wave certainly avoided a significant impact on Bangladesh coast, but other locations like Northern India experienced significant wave heights in the same configuration. Other locations with no extended shelf like the Andaman coast of Thailand, the Indian and Sri Lanka coast or indeed the Banda Aceh area in Indonesia did experience severe runups for the same event. We may assume that other areas of important sediment discharges and extended associated shelf may likely experiment the same conclusions. As an example, it may be the case offshore the Nile delta were ancient tsunamis might have been triggered by geological under-water landslides (Ioualalen et al., 2005).

Acknowledgements. The authors gratefully acknowledge the NGDC for the ETOPO2 gridded global relief data. M. Ioualalen is grateful to the Agence Nationale pour la Recherche, ANR, for supporting this work through the TSUMOD Grant ANR-05-CATT016-02). He also thanks IRD and DME Department for their help in running this work. Finally the authors are grateful to the two reviewers who contributed to a substantial improvement of the first draft manuscript.

Edited by: S. Tinti

Reviewed by: A. Armigliato and another referee

\section{References}

Ammon, C. J., Ji, C. , Thio, H.-K. , Robinson, D., Ni, S., Hjorleifsdottir, V., Kanamori, H., Lay, T., Das, S., Helmberger, D., Ichinose, G., Polet, J., and Wald, D.: Rupture process of the 2004 Sumatra-Andaman earthquake, Science, 308, 1133-1139, 2005.

Chen, Q., Kirby, J. T., Dalrymple, R. A., Kennedy, A. B., and Chawla, A.: Boussinesq modeling of wave transformation, breaking, and run-up. II: 2D, J. Wtrwy, Port, Coast, Oc. Engrg., 126, 48-56, 2000.

ETOPO-2 (World Data Center for Marine Geology and Geophysics: 2-minute gridded global relief data) (2001), National Geophysical Data Center (NGDC), NOAA Satellite and Information Service, http://www.ngdc.noaa.gov/mgg/fliers/01mgg04. html, 2001.

Grilli, S. T., Ioualalen, M., Asavanant, J., Shi, F., Kirby, J. T., and Watts, P.: Source Constraints and Model Simulation of the December 26, 2004 Indian Ocean Tsunami, J. Wtrwy, Port, Coast, Oc. Engrg., in press, 2006.

Ioualalen, M., Huguen, C., Migeon, S., and Mascle, J.: Glissement sous-marin fossile au sein du delta profond du Nil: Simualtion numerique d'un tsunami potentiel associe, Colloque sciences et Technologies Marine du futur: un enjeu pour la Mediterranee, Marseilles, France, 19-20 May, 2005.

Ioualalen, M., Asavanant, J., Kaewbanjak, N., Grilli, S. T., Kirby, J. T., and Watts, P.: Modeling the 26th December 2004 Indian Ocean tsunami: Case study of impact in Thailand, J. Geophys. Res., in revision, 2006.

Kennedy, A. B., Chen, Q., Kirby, J. T., and Dalrymple, R. A.: Boussinesq modeling of wave transformation, breaking, and runup. I: 1D, J. Wtrwy, Port, Coast, Oc. Engrg., 126, 39-47, 2000.

Knight, B.: Model predictions of gulf and sourthern Atlantic coast tsunami impacts from a distribution of sources, Science of Tsunami Hazards, 24(5), 304-312, 2006.

Lay, T., Kanamori, H., Ammon, C. J., Nettles, M., Ward, S. N., Aster, R., Beck, S. L., Bilek, S. L., Brudzinski, M. R., Butler, R., DeShon, H. R., Ekstrom, G., Satake, K., and Sipkin, S.: The great Sumatra-Andaman earthquake of 26 December 2004, Science, 308, 1127-1132, 2005.

Merrifield, M. A., Firing, Y. L., Aarup, T., Agricole, W., Brundrit, G., Chang-Seng, D., Farre, R., Kilonsky, B., Knight, W., Kong, L., Magori, C., Manurung, P., McCreery, C., Mitchell, W., Pillay, S., Schindele, F., Shillington, F., Testut, L., Wijeratne, E. M., Caldwell, P., Jardin, J., Nakahara, S., Porter, F.-Y., and Turetsky, N.: Tide gauges observations of the Indian Ocean tsunami, December 26, 2004, Geophys. Res. Lett., 32, L09603, doi:10.1029/2005GL022610, 2005.

Okada, S.: Surface displacement due to shear and tensile faults in a half-space, Bull. Seismol. Soc. Amer., 75, 1135-1154, 1985.

Smith, W. H. F., Scharroo, R., Titov, V. V, Arcas, D., and Arbic, B. K.: S atellite altimeters measure tsunami: Early model estimates confirmed, Oceanography, 18(2), 11-13, 2005. 
Uddin, A. M. K.: Tsunami, a status paper reflecting Bangladesh coast's exposure to vulnerability, Program Development Office for Integrated Coastal Zonz Managment, PDO-ICZMP, Dhaka, pp. 29, 2005.

Vigny, C., Simons, W. J. F., Abu, S., Bamphenyu, R., Satirapod, C., Choosakul, N., Subarya, C., Soquet, A., Omar, K., Abidin, H. Z., and Ambrosius, B. A. C.: Insight into the 2004 SumatraAndaman earthquake from GPS measurements in southeast Asia, Nature, 436, 201-206, 2005.
Wei, G., and Kirby, J. T.: A time-dependent numerical code for extended Boussinesq equations, J. Wtrwy, Port, Coast, Oc. Engrg., 121, 251-261, 1995.

Wei, G., Kirby, J. T., Grilli, S. T., and Subramanya, R.: A fully nonlinear Boussinesq model for free surface waves. Part 1: Highly nonlinear unsteady waves, J. Fluid Mech., 294, 71-92, 1995. 